\title{
Of Prisons, Tropics and Bicycles: A Conversation with David Arnold
}

\author{
Rohan Deb Roy and David Arnold ${ }^{1}$
}

\begin{abstract}
David Arnold who retired this year as the Professor of Asian and Global History at the University of Warwick remains one of the most prolific historians of colonial medicine and modern South Asia. A founding member of the subaltern studies collective, he is considered widely as a pioneer in the histories of colonial medicine, environment, penology, hunger and famines within South Asian studies and beyond. In this interview he recalls his formative inspirations, ideological motivations and reflects critically on his earlier works, explaining various shifts as well as mapping the possible course of future work. He talks at length about his forthcoming works on everyday technology, food and monsoon Asia. Finally, he shares with us his desire of initiating work on an ambitious project about the twin themes of poison and poverty in South Asian history, beginning with the Bengal famine in the late eighteenth century and ending with the Bhopal gas tragedy of the early 1980s. This conversation provides insights into the ways in which the field of medical history in modern South Asia has been shaped over the past three decades through interactions with broader discussions on agency, resistance, power, everydayness, subaltern studies, global and spatial histories. It hints further at the newer directions which are being opened up by such persisting intellectual entanglements.
\end{abstract}

Keywords

Colonialism, medicine, subaltern, everyday, South Asia

\section{Rohan Deb Roy (R): Many look up to you as an inspiring historian. Which authors and events inspired you the most in becoming the historian you are? Who are your favourite historians?}

David Arnold (DA): I think that the inspiration I received from particular historians depended on the different phases in my personal evolution as a historian. The inspiration for much of my initial thinking about history came from the social history of the 1960s and 70s, particularly from the work of E.P. Thompson and Eric Hobsbawm and, indeed, the whole generation of people writing

${ }^{1}$ We are grateful to Theresia Hofer and Shinjini Das for their help during transcription. An earlier version of this interview was published in Global South (Sephis e-magazine), 6:3, July 2010 . 
social history at that time. Their work seemed to be left wing, more political than much of what went before it, able to open up new and more popular domains of history in ways that seemed not only interesting in themselves but to fit the mood of the time. It took us away from the conventional histories of state, nation and church. Subsequently, I was interested in the linkages between history and anthropology, particularly through the historical anthropology of Bernard Cohn in the South Asia field but also scholars like Eric Wolf and his work on peasants. I continue to think that the link between history and anthropology is a crucial one for historians of South Asia and it continues to influence the way I approach history. Subsequently, Foucault has been the most important single influence on my work and my thinking about history. Of course, Foucault's work takes many forms and it is the early Foucault that I tend to go back to, particularly Discipline and Punish and the Power/Knowledge interviews rather than the later Foucault of The History of Sexuality.

My interest in history has changed over time and so the influences on it have also changed accordingly. I am not sure that I was ever inspired by any one particular book. It is more often the mood or the collective identity of a whole field of history writing that I responded to. I found the Annales School extremely stimulating not for any one single work, though I certainly found Le Roy Ladurie's Montaillou and Marc Bloch's work on feudalism, particularly interesting, but it was the methods and approach of the Annales School in general that appealed to me without my necessarily feeling that any particular book was by itself inspirational.

\section{R: What about Ranajit Guha and the Subaltern Studies collective?}

DA: At a critical stage in my evolution as a historian, and around the time that the Subaltern Studies group emerged, Ranajit was working on the Elementary Aspects of Peasant Insurgency. What inspired me was more his work on that project rather than the book that appeared subsequently. We discussed parts of it, his ideas about inversion, territoriality and so on, over an extended period of time and I greatly benefitted from that. It was not so much Ranajit's published work, which at that point of time principally consisted of the book on the Permanent Settlement in Bengal, that I found inspirational as being involved in the early discussions of the Subaltern Studies group. Elementary Aspects is an important book, although I feel now with hindsight there are many things that it does not do that it might perhaps have done, and many assumptions that it makes about peasants that we might now look at rather more critically. I have in mind in particular the way it tends to see the peasantry and the subaltern classes as a kind of universal category from which one can draw parallels from Germany or France without perhaps fully recognising the historical and social specificity of the Indian situation. 
R: Medicine was obviously not the first theme you worked on. Following your works on the Congress in Tamilnad, the colonial police, hunger and famine, what motivated your forays into the medical archive?

DA: I have always felt that one has to move on as a historian. The worst thing that a historian, or any scholar, can do is to write the same book fifteen times over. It is important to try to address new fields. That said, though, I would like to think that there is a certain consistency in the work that I have done. My recurrent concern and continuing focus is obviously with India, particularly during the period of colonial rule. Although I have moved beyond India from time to time, that is the location that I have always come back to as my safety zone. I was not intending to work on the police indefinitely, even though I thought it was an important subject then and is one that continues to inform the work I do now. But in writing about the police and in thinking about famine, it was in some ways a natural step to go on to consider the medical material. In looking at colonial policing, for example, I found that the police were sometimes obliged to 'police' health conditions, to enforce quarantines, and so on. What we now think of as governmentality created to my mind a kind of continuum between the police and medicine. In Colonizing the Body, I was also interested in the relationship between the state and its ideas of medicine and the popular engagement with disease and epidemics, so it seemed an appropriate lateral shift from thinking about the police and its interactions with the people. I did not anticipate at the time how fertile the medical history field might actually be in relation to India. Nothing much had been written about the medical history of India at the time. Whatever was available was frankly pretty boring-a bit about sanitary policy and not much else. I was, of course, aware of the work of Roy Porter and others, who were beginning to write about the history of medicine in new and interesting ways. So my interest in the history of medicine in India proved to be quite timely.

R: You are considered one of the leading historians of colonial medicine. If somebody like Shula Marks or Warwick Anderson asked you 'What is colonial about colonial medicine?' or 'Where is the postcolonial history of medicine?' how would you respond? And is it possible to delineate features of medical history exclusively relevant for the global south or the third world?

DA: I do not believe there can be-or needs to be-a single definition of colonial medicine. One could, of course, start with a rather minimal definition. It can be simply defined as whatever medicine happens to occur in a given colonial context, whether, for example, in the Spanish New World 
before 1800 or British India or Australia. To that extent, it is about the political contexts in which medicine happens to be practised. But, this definition is extremely narrow and ultimately unhelpful. I have tried in my own work to think about colonial medicine principally in relation to two issues. Firstly, I see the involvement of medicine in a colonial situation like that among the non-white population of India as a process. The whole point for me in talking about 'colonising the body' was to see it not as some kind of absolute control over the body but as a series of discursive and practical interventions by the colonial power that never achieved all its ambitions. It is a process by which medicine impinges on India from outside. It attempts to colonise but remains an imperfect and incomplete process-some efforts perhaps succeed, others do not. Some objectives are taken up internally (by Indians) and so on. Secondly, I try to think about ways in which colonialism provides us with a specific site of enquiry, one with characteristics of its own that significantly inform and shape the nature of the medicine practised within it. So, although we might generalise about colonialism as a whole and trace common characteristics in colonial medicine in general, we still need to recognise that, as in the case of India, there are certain constitutive elements that come from the actual or perceived nature of its physical environment, its cultural conditions, the local mix of colonial power and colonial subjects. We need to see colonial medicine as something which is always in some respects local, and not just a uniform manifestation of some global (or pan-colonial) phenomenon. But I do think that the notion of colonialism, and indeed of colonial medicine, constantly needs to be revisited in the light of new questions. Warwick Anderson's question about 'where is the postcolonial?' is a pertinent question, but, having worked mainly on the colonial period, it is not a question I feel particularly competent to answer, except to say that the more established the idea of the 'postcolonial' becomes, the more urgently we need to have at least a working definition of what constitutes the 'colonial'.

There are, I think, various ways in which we can continue to use the idea of colonial medicine to enlarge the field of enquiry about colonialism and about health and medicine more generally, and one can perhaps do this by standing outside the parameters of what most obviously constitutes the colonial (administrative structures, official policies, colonial agencies, racial identities and so on). For instance, one could, however speculatively, consider the whole nature of health and disease, in the context of South Asia between the 1770s and the 1980 - that is, well beyond independence and into the post-colonial era-in terms of two separate but intersecting modalities or paradigms of poison and poverty. The understanding of many diseases, for 
example, revolved around those two ideas or shifted from one to the other over time. So, in certain times malaria and cholera were understood as being caused by some kind of poison invading the body from outside. At other times, these and other epidemics were more closely related to understandings of poverty, in itself seen as a fundamental characteristic of India's environment, its economy and society. Poison takes on a distinctive significance in India not just from the long history of poisons that double as therapeutics but also, for instance, from its connection with snake-venom, which in turn has a particular resonance with the perceived nature of India as a perilous environment in which to live. The idea of poison also captures a colonial belief in the insidious and dangerous nature of indigenous medicine: In British eyes, many practitioners of indigenous medicine were, in effect, purveyors of poison. Poisoning has further associations outside of the immediate sphere of medicine, particularly in its association with crime, as in thugee. There are various ways in which the trope of poison continued to inform the understanding of health and well-being in India throughout the colonial period and beyond, as for instance through discussions of environmental pollution (itself a kind of poison) and the harmful effects of urban and industrial waste. My reason for taking 1984 as an end-date is to include the Bhopal tragedy in which poisoning (by gas leaked from a foreign-owned plant) caused death and injury to a very large number of people. Equally, if we take up the idea of poverty in relation to the famines of late eighteenth and nineteenth centuries we can ask various questions as to the linkages made with mortality and disease. How far were famines, and the mortality they caused, understood in terms of the underlying poverty of the people or due, as it were to non-economic factors, to invading epidemics and their specific 'poisons'? Is famine seen to be caused or encouraged by a kind of poverty that is not just economic but is seen to arise from the nature of the Indian environment or from certain kinds of 'impoverishing' social and cultural practices? What I am trying to suggest, then, is that by looking at these kinds of tropes (and one could choose others), over the whole of that long period of 200 years or so, one can sense long term trends and shifts in the understanding of health and disease. Further it is possible to come back to the way in which the colonial informs, influences and gives a particular meaning and context to developments in India. I certainly still think there is a great deal that can be done with the idea of colonial medicine, and clearly I do not accept the view of some skeptics who think that there is nothing distinctive at all about colonial medicine. I do recognise the need to continue to unpack the possibilities latent within that term, rather than assuming it as self-evident or that it has already exhausted its utility. 
R: There are renewed efforts to initiate greater traffic between medical histories and subaltern studies in South Asia. The category 'medical' has undergone critical interrogation by medical historians themselves, e.g. Roger Cooter. Similarly, the plausibility of convenient and transparent access to subaltern histories has been questioned from within the subaltern studies collective itself. How would you react to proposals for such a marriage at this point?

DA: The attempt to engage the history of medicine more closely with subaltern studies is a valuable and significant move. It forms a kind of continuing trajectory of the original Subaltern Studies project. Even though the Subaltern Studies collective has dissolved and disintegrated, nonetheless the idea of studying the subaltern has remained a very powerful one. In many senses, it remains an unfulfilled project. I think it is perfectly legitimate and desirable for people to take up that project and seek to develop it in new and different directions. The work I am presently doing on 'everyday technology' partly attempts a subaltern studies approach to the history of modern technology. Looking at subaltern medicine and healing is another way of continuing to do subaltern studies and extending and enriching it in various kinds of ways. It is important, too, because it demonstrates the extraordinary range and variety of what we mean by 'medicine'. The very idea of medicine can, of course, be critiqued, but it is a convenient umbrella term for thinking about the body, about bodily practices, about ideas of health as well as disease, and about the nature and exercise of authority in society. I would not want to abandon the overarching utility of the term. So if it is a question of whether there should be a stronger connection between subaltern studies and discussions of medicine and health, then absolutely yes. It is not something I am particularly pursuing in my own work at the moment, but I have every sympathy with it.

R: Talking of Subaltern Studies, I would like to return to some of your earlier writings in the series. In successive essays, i.e. on the Bombay plague ("Touching the Body") and colonial penology as well as in the classic Colonizing the Body, 'resistance' figured as a central problematic in studying the contours of various disciplinary regimes of colonial power and knowledge. You masterfully showed how 'resistance' and persuasion towards hegemony could coexist as mutually enabling processes. Studies in various innovations of colonial power appeared to nuance significantly the image of the perfectly mechanized docile subject body. However, in more recent works i.e. those on environment (Nature, Culture Imperialism and The Problem of Nature) and in the more obvious work of spatial history (The Tropics and the Traveling Gaze) your preoccupation with the 
theme of 'resistance' appears to have been considerably displaced. How would you explain this? Has the subalternist in you shifted focus from spectacular and significant resistances to studying minuscule and quotidian habitations of modernity?

DA: I would have to go back to 1960 s and 70 s to answer that question. That was a period in which there was a rapid growth of academic interest in protest and resistance of various kinds. Much of Thompson, Hobsbawm and Rudés work was really about the nature of resistance, whether about peasant resistance in particular or subaltern resistance more generally. And, of course, Ranajit's work at that time was centrally about resistance too. It was one way of responding to a widely held notion of hegemony as representing a nearcomplete domination of society without allowing for the possibility of anything operating in opposition to it or qualification of it. Foucault, too, greatly exaggerates the power of the discursive themes of penology and bodily discipline he is talking about. Resistance always has to be part of the story, whether it is effective or not. It was timely to talk about resistance in the 1970s and at that time it was methodologically and intellectually important to do so, particularly in the Indian case where, in the 1960s and 70s, many people thought of India as a society that was never going to be revolutionary. China was revolutionary, India was not. In this view, India was dominated by caste, landlords and religion - it was not about resistance or even substantially about change. So, in writing about resistance one was reacting to ideas of Indian passivity. But that argument has been made and there is no point in continuing to make the case against assumptions of Indian passivity. However, I would suggest that the question of resistance can be understood as an aspect of a wider issue of agency. Writing about resistance involved tracing some form of agency among the subaltern classes-their world-view, their mentality and how it shaped their actions, as in riots and rebellions. The question of agency has been one that has continued to inform my work. What kind of agency, if any, for instance, does a prisoner have in a colonial jail? Does he or she have the ability to ignore the prison regulations, or even to defy them? In many such cases the answer is ultimately 'no'. But in the short term it might be 'yes'. There are ways in which situations of power are transformed, qualified, or indeed reinforced, by the very fact that there is resistance. So, to my mind agency and resistance are very much bound up together.

The work I am doing at the moment on everyday technology is in some respects about agency too. To what extent does the arrival of the sewing machines, or bicycles, or rice-mills in India from the nineteenth century entail some form of agency, and for whom? I do not want to go back to a technologically deterministic position where one argues that the introduction of such 
technologies in itself automatically transformed people's lives. But I would suggest that the acquisition of a bicycle does create the possibility for individuals to change their lives, albeit in a small way. There are elements of resistance to the introduction of new technologies, but that is not the primary response I find in my research. There was some resistance to the introduction of rice-milling, for instance, as opposed to the traditional means of handhusking rice and that resistance took a variety of forms (including a Gandhian critique of all mechanized milling). But it is the ways in which the machine was adopted and assimilated without a large measure of popular resistance that interests me most. Perhaps the point should be less about resistance than denial. If we take the case of bicycles, for instance, the question is not one of general resistance to a new technology as such, but it can be about who has the ability to prevent other people from owning or using a bicycle. Up to the 1960s (and perhaps beyond) bicycles were denied to untouchables and many women, particularly low-caste women. So, the question of agency here transforms itself into one of denial. More generally, perhaps, we need to recognise certain distinctions, which I would want to over-exaggerate, between the nineteenth and the twentieth centuries. The nineteenth was a century in which resistance was widely characteristic. One can think not merely about the more spectacular episodes, like the great revolt of 1857 , but also all the other peasant revolts. When we move into the twentieth century, unless you are talking about the nationalist movement, or the things that became subsumed into the nationalist movement, I am not sure whether resistance remains such a central, paradigmatic force. It might be supercilious to say that in the nineteenth century people had riots while in the twentieth century they had bicycles, but there is something distinctive about the way in which society changes over time. The characteristics of the nineteenth and early twentieth centuries that were particularly looked at in the early phase of the Subaltern Studies collective were not necessarily those of India as it began to change and emerge in the 1920 s, 1930s and subsequently. So, I hope I have not lost sight of the notion of agency and of subaltern agency in particular. But I see it as having shifted in character as times changed, and my work has accordingly tended to move away from that primary emphasis on resistance to the idea of denial, or utility, or assimilation, as constituting a rather different kind of agency.

\section{R: Is it also related to the ways in which the left radical academy has moved away from the question of resistance to understandings of the everyday and everydayness?}

DA: Yes. The notion of the everyday is one that has acquired relevance for all kinds of intellectual and academic reasons, but it is something that I think has 
not been adequately explored in the Indian context. By talking about the everyday it is possible to engage with subaltern experience in new and interesting ways. And the extent to which bicycles and sewing machines and rice-mills were disseminated by 1920 s and 30 s is very important to subaltern lives. Although it is quite difficult to recover the evidence for that, there are fragments, there are stories, bits and pieces in the newspapers, that do enable us to begin to construct a rather different notion of subaltern society by the middle of the twentieth century.

\section{R: Are your ongoing projects on 'monsoon Asia' and food likely to consti- tute parts of a single project on everyday technology? Is your most recent book (The Tropics and the Traveling Gaze) and the project about 'mon- soon Asia' your response to the global turn in history-writing?}

DA: My immediate task is to write a book about everyday technology in India for the period from 1880s to 1960s. This is a project that has been funded by the ESRC in the UK. However, the wider project is indeed about monsoon Asia. We had a conference here at Warwick a few weeks ago (around AprilMay 2010), which looked at everyday technology not just in South Asia but also Southeast Asia and there has been some engagement with East Asia as well. One of my responses to the question of how we address global history has been to look (as a number of historians are now beginning to do) at an extended context, ranging across several parts of Asia, and at technologies and material objects that emanate not just from the colonial power or that are not just the product of the internal forces of capitalism within the colony. In a sense, I am echoing Sanjay Subrahmanyam in trying to identify (albeit for a much later period than he is concerned with) a connectedness that links South Asia, Southeast Asia and East Asia in the late nineteenth century through to the middle of the twentieth century. For me, that connectedness is partly about the movement of certain commodities and about commonality in terms of climate and physical environment, but it is also, for example, approachable in terms of rice-production, rice-consumption, the parallel growth of ricemills and the nutritional disease beriberi occurring across the whole arc of monsoon Asia. I am not particularly interested in trying to write a global history that tries to encompass the entire globe. But I do recognise the need to step outside the limits of a purely regional approach and employing the concept of 'monsoon Asia' is a convenient way of doing this. I also want to engage with the idea of globalisation and globality through the kinds of commodities I am looking at. So, if we are talking about sewing-machines in India, for example, we are looking at a type of machinery that comes primarily from the United States and that says a lot about the extent to which the US was a 
significant economic and cultural influence upon India even during the period of British colonial rule. I am interested in the way in which certain kinds of global goods, like sewing-machines, became in effect localised through the specific nature of local use, through their social and cultural appropriation and incorporation, as dowry items for example, or for the making of local types of clothing. The multiple engagement between colonialism, international and indigenous capitalism, local consumerism and changing patterns of work and modes of material existence-this is what I am trying to study in my present work. The book about everyday technologies that comes out of this is going to be specifically about India, but I hope that it will engage with some of the issues that the rise of globalisation and global history have made prominent.

Equally, questions of food and medicine have not disappeared from my consideration. Food is something I have come back to in a number of different contexts and indeed the discussion of rice mills in my present project offers another dimension to the question of food as part of the changing nature of food production, the spread of rice-consumption, the mechanisation of foodprocessing and so on. To go back to what I was saying earlier, I have begun to consider the possibility of writing a book around the twin problematic of poison and poverty, but I am not quite sure how this would work out at the moment. It would be one way of revisiting and revising some of the work that I have done on food and famine in the past, and on particular diseases like beriberi, but, as I tried to explain just now, it would also be a move outside the obviously colonial context and try to treat the period from the 1770 s to the 1980 s as a whole.

\section{R: Does it mean that culturally sensitive economic histories will be a more overt feature of your current work than ever before?}

DA: (Laughs). I have never been an economic historian. I do not spend a lot of time thinking about economic policies or the purely economic nature of the particular commodities I am looking at. Nonetheless, I do recognise that the kinds of commodities I am discussing do exist in a market-place, that they are bought and sold (as well as stolen), and I do need to engage with questions about the scale of importation, changing prices etc. So to that extent perhaps there will be more economic background to this than to any of my previous work. I am also trying to re-examine the nature of capitalism in twentieth-century India and particularly what I think of as swadeshi capitalism. The long-term nature of the swadeshi movement has not, to my mind, been fully explored as an imaginative idea as well an economic ambition. In Sumit Sarkar's work the emphasis is on Indians making things for Indians, but there should be an equal emphasis upon Indians selling things to other 
Indians and for what they see as purposes beneficial to India and Indians. In the case of bicycles, for instance, it was not until the 1950s that these were being produced in India on an extensive scale. But well before that, there were plenty of Indians who sold them, used them with enthusiasm and saw them having as a positive social and cultural value for Indians' health, mobility and self-sufficiency, and even as having a political significance as part of India's cherished modernity. In that sense, the notion of swadeshi capitalism needs to be expanded to address the ongoing social and cultural context as well as its economic meaning and I see everyday technology as one way of trying to do that.

R: You have shown how 'natural' categories like environment, tropics etc. are historically produced. Social constructivism in science studies has been discredited by Bruno Latour for having been guilty of sociological reductionism. One disturbing fallout of such critiques has been a biological turn in history writing. Bestselling books like Echo objects and $O_{n}$ Deep Histories and the Brain have boastfully discovered answers to various historical questions in scientific models. Dipesh Chakrabarty's essay on history writing and climate change urges greater recognition of humans as geological actors and insists on the imperative of writing collective species histories of human beings. The contending parties in the blame game appear to allege one another of scientism and sociological reductionism respectively. Would you prefer to take a side in this debate?

DA: I am not sure I would want to because what I have tried to do in my own work is to write about the things that interest me in ways that appeal to me rather than beginning with a grand conception of how the field should advance. My involvement in environmental history in part grew out of the Subaltern Studies project and contemporary interest in environmental issues. I hope that my approach to environmental history incorporates the materialist proposition that there are real things out there in the environment, like microbes and diseases. But, at the same time, they do not exist in isolation but exist in a kind of social dialectic in which they also function as ideas, predicated on all sorts of cultural practices and assumptions. So I would not accept a stark dichotomy between a materialist reading of, say, the environment, and a culturalist one as if the two were entirely different and contrasting things. They feed on one another, and it is the task of the historian not to be a pseudoscientist and pretend to have scientific insights, or simply to be, as it were, an obsessive culturalist, but to somehow mediate between the two. Historians are well placed to gather certain kinds of evidence from and about the material world but they also need to address a host of subjectivities drawn from the 
social and cultural domain. I am disinclined to take up your invitation to take sides because I think that taking sides does not actually advance the field. It is rather by interacting with those two possibilities that the history of environment, medicine and science is able to grow and develop new insights.

But to go back specifically to the environmental question, one of the things that I am interested in is space, the spatiality in which colonialism and the other socio-political forces operate. The Tropics and Traveling Gaze tried in part to look at the notion of the tropics as a distinctive space in which diseases, plants, people etc. were seen to operate in certain kinds of ways. It was an attempt to study India at a particular point in time but also to move the historical discussion of India into a wider environmental paradigm. My present work on everyday technology is also about space, but about the different kinds of spaces that modern technologies come to occupy-the domestic space in which a sewing-machine is situated and put to work, or the space of the street in which different kinds of technologies coexist and at times collide-bicycles, cars, trams, buses, ox-carts, etc. I am trying to continue to develop the notion of spatiality but not by talking in terms of the tropics, a grand and overtly environmental idea, but in terms of certain more immediate and intimate modern spaces. In villages, for instance, the arrival of the rice mill ushered in a new kind of rural space that was significantly different from what had gone before. I am not really interested in a presumed polarity between the material and the discursive. My interest is in finding situations and tropes that enable us to engage with both of these simultaneously.

\section{R: In relation to your works, we have talked about notions of power, resis- tance, agency, subalternity, space, everyday etc. How would you situate yourself as a historian?}

DA: That is difficult because I have not spent much time in trying to define myself. But I suppose there are two or three basic commitments behind my scholarly work. I certainly see myself as, in part, continuing the wider subaltern studies project. Although I often write about the state, or as in a recent article about diabetes in relation to the Indian middle classes, it has always been my ambition to get back to the subaltern domain. I do not think that it is an unproblematic domain, nor an isolated and self-contained one, but I would like to regard it as the enduring centre of gravity for most of the work I do. I believe understanding and exploring subalternity is critically important for India, for the history of India and for the writing of history in general. There is a part of me that would always want to write about the histories of the poor. That is where I really feel my locus is. My understanding of Marx, Gramsci, Thompson and Foucault continually brings me back to the question 
of the poor. All the things that I have written about — policing, crime, famine, disease, technology - all gravitate in the end around the question of the poor. But, at the same time, I would like to regard myself as a historian of India, and of South Asia, and that is the regional field that has, of course, been the main focus of my work over several decades. I believe that it is much more useful (and practicable) to be a historian of India than pretend to be a global historian, which I think of as an unrealisable ambition. Equally, I would always like to write about India beyond the immediate arena of the village and the town, beyond the single province or constituent state. There is a certain collective dynamism about South Asia as a whole that has been particularly in need of historical enquiry and understanding. I have found a lot of enjoyment in studying South Asia over the years. The kinds of topics I have taken up have been ones that have been of personal interest for me and I hope I have communicated something of that personal involvement to others. History has to be written around commitment; it has to be written around belief, enthusiasm and engagement.

\section{R: But the poor seems to have lost the exclusive attention it used to enjoy within subaltern studies.}

DA: To my mind the question of the subaltern is always ultimately connected to issues of poverty and deprivation, with the lack of structural power. I am nervous about notions of the subaltern that extend extensively into the middle class, or the aristocracy, or that simply represent the whole of India as being in some way colonially subaltern. My understanding has always been that it is really about the subordinate sections of society. The value of using the term 'subaltern', rather than the older class terminology, has been that it allows for a certain fluidity in defining how all the different and various subaltern groups are collectively understood. Opening up the subaltern category not just to tribals, peasants and dalits but also, say, to women and various low-ranking urban groups makes a lot of sense. It is, of course, important to recognise that there is no clear line between what we call the subaltern and the elite: Obviously society is far more complicated and entangled than that.

However, to go back to technology for a moment, there are ways in which we can see manifestations of subalternity through technological engagement. As I have said, subalternity can be manifested in terms of the denial of access to technology by certain kinds of people, like untouchables and women. And yet, there is also the possibility of an escape from subalternity through the opportunities that new technologies make available to people who find ways of becoming small-scale entrepreneurs, who manage to lift themselves out of the peasant community by becoming petty capitalists and small-time 
entrepreneurs. I think there are ways in which we can continue to explore that subaltern idea-not as something that is absolute but as a fluid concept that is extremely useful in the context of India and its history but also more generally around the globe. One of the most important achievements of the Subaltern studies project was that it opened up a dialogue between the history of India and the histories of other parts of the world. If one goes back to the 1960s and 70 s, one of the saddening things about South Asian studies was the way in which it was often extremely esoteric and introspective, overly concerned with what was understood to be the idiosyncratic nature of Indian society- the peculiar and complex nature of landlord-peasant relationships, for example, or the specific nature of caste and community. Subaltern Studies, or perhaps the invocation of the subaltern studies idea quite as much as the work of the group itself, has been extremely influential in opening up a whole new way of thinking about social categories and the interactive domains they inhabit.

\section{R: To digress a little: How critical has teaching and supervising been in shaping your research?}

DA: I have been extremely fortunate in the Ph.D. students I have had, particularly during my time at SOAS. I am not sure that I contributed much to their evolution but they certainly contributed a lot to mine. I have particularly enjoyed being able to discuss and share ideas with research students and to see through their work the unfolding prospects and possibilities for historical research in the South Asian context. It is really rewarding to see how well they have done following their Ph.D.s. One or two of my books, particularly the one on Gandhi, came directly out of my undergraduate teaching. Teaching encourages one to be schematic about a subject, to think about the wider problematic it presents, and the need to try to put it across in an engaging and thought-provoking way. I would not like to be in a position of a researcher whose output is solely communicated through written papers and occasional seminars. I have particularly enjoyed being at Warwick, where the undergraduate students are very interested and articulate, and being here has been an important stimulus to me at this stage of my career and in thinking about what further work I might want to do.

\section{R: When you look back, how significant has the contribution of South Asian studies been to the general historiography of medicine in the last twenty years?}

DA: The contribution that South Asia has made to the history of medicine over the last twenty years has been enormous. I am not thinking of my own 
work but that of a whole generation of scholars who have taken the discussion about medicine in South Asia and made it accessible and relevant to those working in other areas such as Africa and Southeast Asia. At present the standing of South Asian history as a whole is very high. There was a time in the 1960s and 70s when to study South Asian history was to lock yourself in a closet: We have come out of that closet in a big way. Whether South Asia can continue to command the same degree of intellectual and academic authority in the future I do not know, but certainly for the moment it has a very important presence in thinking about colonialism, modernity, identity, community, and the postcolonial. Perhaps that present position creates problems for the future-as to how South Asian history, and especially South Asian medical history, can continue to be innovative and dynamic. We will see.

\section{R: How can histories of medicine repay that debt to South Asian historiography?}

DA: It is impossible for me to predict what might happen in the future, particularly in a field as diverse as the history of medicine where different scholars do very different things. I do not think there is a single history of medicine out there that speaks to South Asian history as a whole. But I think that the problematic of the body, which historians of medicine have helped to explore, can become more fully integrated into the wider historiography of South Asia. Many aspects of the history of health still need to be interrogated, not just in a strictly medical sense but also in terms of understandings of social and physical well-being. As I suggested earlier, there are ways in which we can come back to questions of poverty and ask how the history of medicine can contribute more explicitly to an understanding of what poverty is and means in a South Asian context. If we hit the right problematic, we can open up the history of medicine in ways that continue to demonstrate its vitality and relevance for the South Asian field as a whole. There are perhaps ways in which we can conceptualise South Asia as a whole in a more dynamic fashion than we have often done so far. Too often, studies of the history of medicine are about India (or some part of India) or solely about Nepal or Sri Lanka. We need to say more about the ways in which diseases, people and commodities move around South Asia or beyond South Asia into the monsoon Asian arc (as well as in relation to Europe and the metropole). Part of that endeavour also involves moving away from the nation-state by emphasising the constant movements of epidemics, of medical ideas and personnel, throughout South Asia and into the neighbouring regions.

\section{R: It was a real pleasure talking to you. Thank you}

